\title{
A simple sol-gel route to the construction of hydroxyapatite inverted colloidal crystals for bone tissue engineering
}

\author{
Carlos João ${ }^{\mathrm{a}}$, Rute Almeida ${ }^{\mathrm{a}}$, Jorge Silva ${ }^{\mathrm{b}, * *}$, João Borges ${ }^{\mathrm{a}, *}$ \\ ${ }^{a}$ CENIMAT/I3N, Materials Science Department, Faculty of Sciences and Technology, FCT, \\ NOVA University of Lisbon, 2829-516 Caparica, Portugal \\ ${ }^{b}$ CENIMAT/I3N, Physics Department, Faculty of Sciences and Technology, FCT, \\ NOVA University of Lisbon, 2829-516 Caparica, Portugal
}

\begin{abstract}
Hydroxyapatite (HAp) scaffolds with uniform pore size and interconnected pore network were constructed based on the inverted colloidal crystal (ICC) geometry and a simple sol-gel formulation. Monodisperse polystyrene microspheres were self-assembled and annealed into a hexagonal close packed structure. HAp sol-gel was infiltrated in this template followed by thermal treatment for simultaneous HAp matrix sintering and polymeric colloidal crystal calcination. The resultant ICC scaffolds exhibit an ordered architecture that was able to offer a favourable environment for human osteoblasts adhesion and proliferation, an essential feature for bone ingrowth in tissue engineering applications.
\end{abstract}

\section{Highlights}

- Infiltration of a colloidal crystal template with a hydroxyapatite sol-gel system.

- Production of ceramic inverted colloidal crystal.

- Construction of ceramic structures with uniform and interconnected pore network.

*Corresponding authors: Tel.: 00351212948564; Fax: 00351212957810 E-mail address: jpb@fct.unl.pt (J. Borges)

${ }^{* *}$ Tel. 00351212948576; Fax: 00351212948549 E-mail address: jcs@fct.unl.pt (J. Silva)

Preprint submitted to Material Letters

July 29, 2016

(C) 2016. This manuscript version is made available under the Elsevier user license http://www.elsevier.com/open-access/userlicense/1.0/ 
- Scaffolds exhibit suitable in-vitro environment for osteoblast adhesion and proliferation.

Keywords: Hydroxyapatite, sol-gel, inverted colloidal crystals, bone tissue engineering

\section{Introduction}

Bone tissue engineering requires the development of $3 \mathrm{D}$ scaffolds that provide the necessary support for cell adhesion, proliferation and differentiation, and whose architecture contributes to cell migration and regenerative activity through an adequate supply of oxygen and nutrients 11. As biocompatible scaffolding materials, calcium phosphates, in particular hydroxyapatite, are frequently used due to their chemical similarity with the inorganic phase of human's bone and their bioactivity, noninflammatory and osteoinductive properties [2]. Although a number of scaffold fabrication technologies have been employed, non-uniform pore structures with limited interconnectivity are shortfalls recurrently reported [3]. Inverted colloidal crystal (ICC) systems have been recently proposed for the production of isotropic 3D structures with uniform pore size and high interconnectivity, higher diffusion rates and uniform cell distribution [4, 5].

In this work, a simple method for the design of 3D HAp scaffolds exhibiting the ICC architecture is suggested. Combining a polymeric colloidal crystal (CC) template with a ceramic sol-gel route, we present a procedure for the production of scaffolds with high porosity and controllable pore network along with the morphological, chemical and in-vitro characterization of the resultant products.

\section{Materials and Methods}

The $\mathrm{CC}$ template was prepared by annealing at $130^{\circ} \mathrm{C}$ for 4 hours the $(270$ $\pm 8) \mu \mathrm{m}$ diameter polystyrene (PS) microspheres, produced using a microfluidic apparatus, placed in a cylindrical mould and self-assembled into a hcp structure 
under orbital agitation. The CC template was infiltrated with the HAp + binder gel mixture under vacuum and heated for drying $\left(\right.$ at $\left.75^{\circ} \mathrm{C}\right)$, template removal $\left(450^{\circ} \mathrm{C}\right.$ and $\left.550^{\circ} \mathrm{C}\right)$ and sintering $\left(600^{\circ} \mathrm{C}, 800^{\circ} \mathrm{C}\right.$ or $\left.1100^{\circ} \mathrm{C}\right)$. HAp was produced through a sol-gel route using ethanolic solutions of calcium nitrate 4-hydrate and phosphorous pentoxide as precursors [6]. The binder consisted of a $25 \mathrm{wt} \%$ poly(vinyl acetate) solution in acetone. A schematic representation of ICC production is shown in Fig. 1. The ICC scaffold was characterized by scanning electron microscopy (SEM) for morphological assessment, Archimedes method for porosity evaluation, X-ray diffraction (XRD) for calcium phosphate phase composition, crystal size and crystallinity calculation, Fourier-transform infrared spectroscopy (FTIR) for chemical analysis and in vitro culture and fluorescence microscopy of human osteoblasts for cell adhesion and proliferation. Further details of the experimental procedure can be found in the supplementary material.

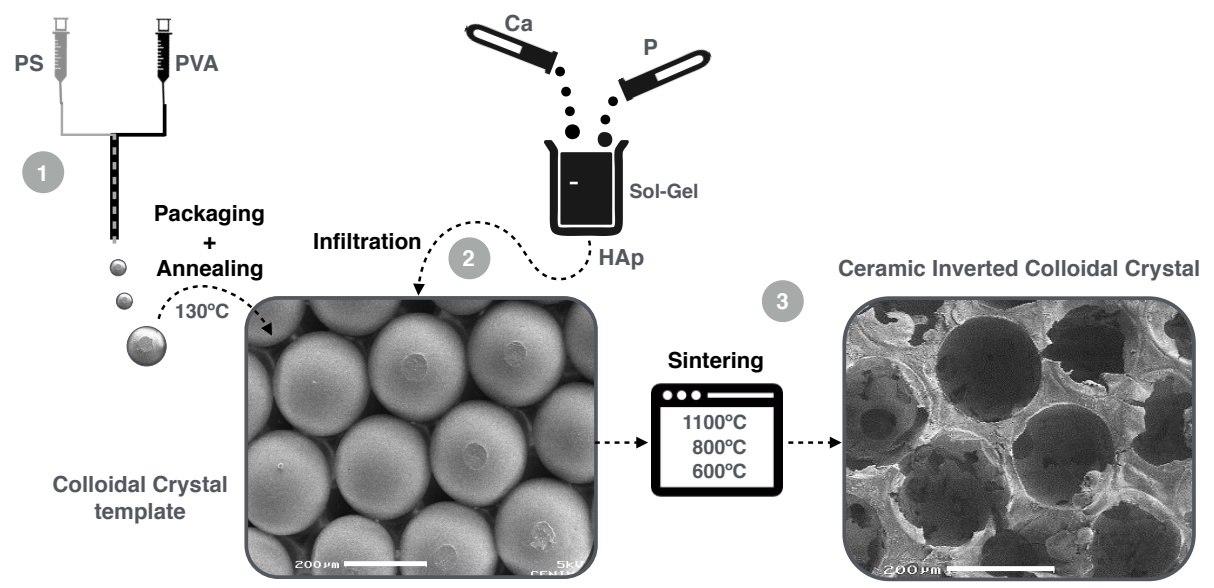

Fig. 1: Production of HAp ICC scaffolds: 1) Microspheres and colloidal crystal template construction; 2) Sol-gel synthesis and template infiltration by vacuum; 3) ICC production in a single step of spheres calcination and ceramic matrix formation . 


\section{Results and Discussion}

\subsection{Ceramic ICC scaffold}

Fabrication of the ceramic ICC implied a single-step procedure of sphere removal and sintering, composed of 4 temperature stages. Gel drying occurs during the first stage with the loss of solvent and physically adsorbed water leading to a solid structure able to maintain its shape. In stage 2 , the temperature above PS and PVAc glass transitions (supplementary material Fig. $\mathrm{S} 2$ and S3) caused the PS template softening. Above $250^{\circ} \mathrm{C}$, pyrolysis of the dried gel molecular network began. Pyrolysis created tiny "holes" in the skeletal network that contributed to pore volume and surface area increase with no associated shrinkage. At the hold temperature the pyrolysis of organics was complete and HAp crystallization began. At stage 3, the PS template was completely calcined. The ICC became a porous structure composed by an assembly of ceramic particles.

The thermal treatment's last stage ensured the sintering, during which the majority of the densification and microstructure development took place. The plateau temperature was chosen to ensure that crystalline HAp was present (Fig. S1). At the lower temperatures $\left(600^{\circ} \mathrm{C}\right.$ and $\left.800^{\circ} \mathrm{C}\right)$ the densification was not effective. At the higher temperature $\left(1100^{\circ} \mathrm{C}\right)$, the ICC's present a fully interconnected structure with 80 vol.\% porosity and pore sizes of $(196 \pm 13) \mu \mathrm{m}$

(Fig. 2A). The scaffolds also present sub-micrometer porosity and roughness on their surface (Fig. 2C).

\subsection{Matrix characterization}

In order to characterize the ceramic matrix that composes the ICC scaffolds, DRX and FTIR analysis were conducted in the samples sintered at different temperatures (Fig 3). From the diffractograms it is possible to infer that temperature plays an important role on the formation of crystalline hydroxyapatite. As the sintering temperature is increased from $600^{\circ} \mathrm{C}$ to $1100^{\circ} \mathrm{C}$, several of the HAp peaks become more distinct and narrower which suggests an increase in 

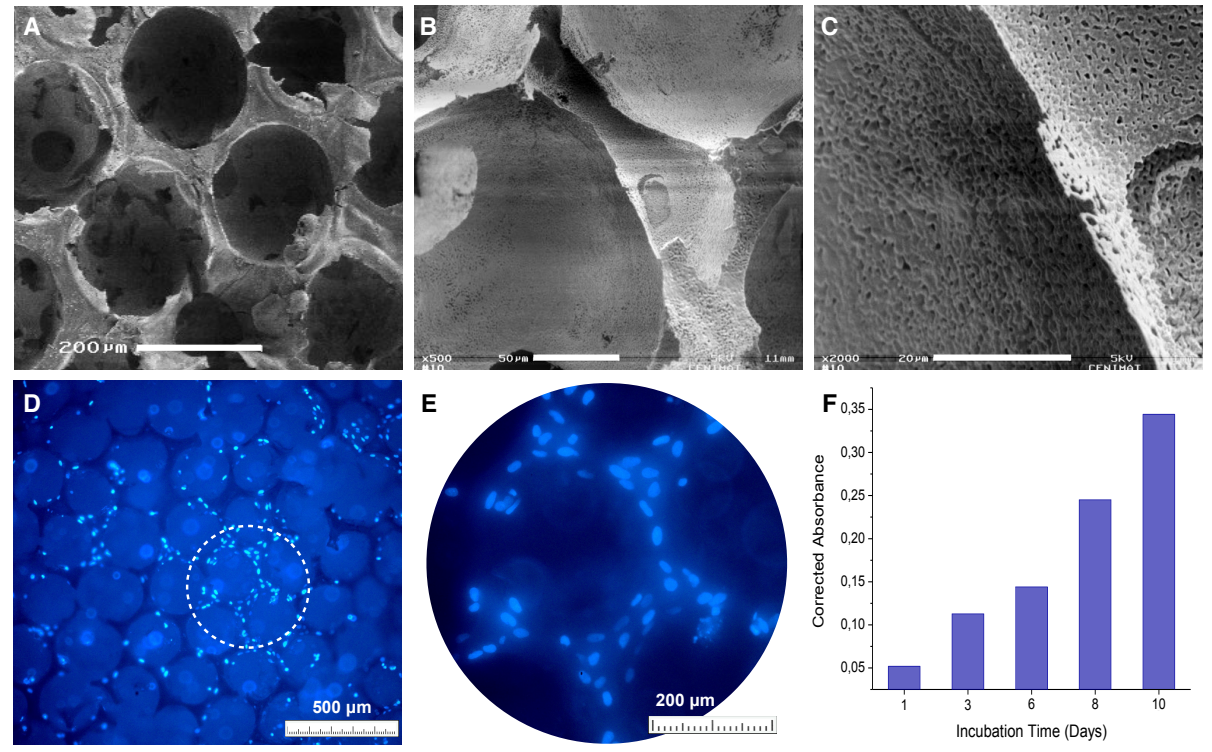

Fig. 2: Images of HAp ICC scaffolds before (SEM) and after (Fluorescence) 10 days cell culture incubation. SEM images of the ICC showing its macroporosity (A), pore walls (B) and microporosity $(\mathrm{C})$. Fluorescente microscopy images of human osteoblasts (SaOs-2) on the HAp ICC (D and E); F - Proliferation assay with corrected absorbance.

crystallinity. Crystal size growth is verified from $(25 \pm 3) \mathrm{nm}$ to $(47 \pm 5) \mathrm{nm}$ and $(62 \pm 3) \mathrm{nm}$ for $\mathrm{T}=600^{\circ} \mathrm{C}, 800^{\circ} \mathrm{C}$ and $1100^{\circ} \mathrm{C}$, respectively. Moreover, the crystallinity degree augments from $31 \%$ to $51 \%$ and $98 \%$ for the same temperature range.

Using stoichiometric hydroxyapatite it should be possible to sinter, without phase purity problems, at temperatures up to $1300^{\circ} \mathrm{C}$ [7. However, a minor misbalance in the calcium/phosphorus ratio (from the standard molar ratio of 1.67) can lead to the appearance of additional crystalline phases during heat treatment. It can be seen that $\beta$-TCP $\left(\beta-\mathrm{Ca}_{3}\left(\mathrm{PO}_{4}\right)_{2}\right)$ appeared at all the sintering temperatures. As the temperature rises to $1100^{\circ} \mathrm{C}$ a fraction of $\beta$-TCP phase transforms into $\alpha$-TCP $\left(\alpha-\mathrm{Ca}_{3}\left(\mathrm{PO}_{4}\right)_{2}\right)$. The $\mathrm{CaO}$ phase was observed after sintering at $800^{\circ} \mathrm{C}$ and above. This data indicates that in this experiment, as the sintering temperature increased, HAp partly decomposed into $\beta$-TCP $/ \alpha$ TCP and $\mathrm{CaO}$, following the reaction proposed by Fahti et al. 8 : 


$$
\mathrm{Ca}_{10}\left(\mathrm{PO}_{4}\right)_{6}(\mathrm{OH})_{2} \rightleftharpoons 3 \mathrm{Ca}_{3}\left(\mathrm{PO}_{4}\right)_{2}+\mathrm{CaO}+\mathrm{H}_{2} \mathrm{O}
$$

These calcium phosphates have different solubilities (HAp being the least soluble) [7, which in the case of ICC matrix biphasic composition can influence the scaffold dissolution/bioresorption rate in in vivo applications.

In Fig $3 \mathrm{~B}$ the FTIR spectra of HAp ICC's sintered at different temperatures is presented. The most characteristic chemical groups in a HAp FTIR spectra are $\mathrm{PO}_{4}^{-}, \mathrm{OH}^{-}$and $\mathrm{CO}_{3}^{2-}$. The first indication of the formation of HAp is in the form of broad band centered at about $1000-1100 \mathrm{~cm}^{-1}$. The bands at 960

- $965 \mathrm{~cm}^{-1}$ and at $560-601 \mathrm{~cm}^{-1}$ correspond to the symmetric P-O stretching vibration of the $\mathrm{PO}_{4}^{3-}$ ion $[9]$. $\mathrm{CO}_{3}^{2-}$ group forms a weak peak at $877 \mathrm{~cm}^{-1}$ and a wider band between 1459 and $1546 \mathrm{~cm}^{-1}$ that suggest the presence of a type A carbonated hydroxyapatite (hydroxyl ions are replaced by carbonate ions) [8]. At $1100{ }^{\circ} \mathrm{C}$ the vibrational assignment of $\mathrm{CO}_{3}^{2-}$ is absent from the FTIR spectra evidencing that carbonate substitution no longer exists. The bands assigned to the stretching modes of hydroxyl groups of HAp $\left(3571 \mathrm{~cm}^{-1}\right.$ and $\left.632 \mathrm{~cm}^{-1}\right)$ can also be observed in the spectra $[9]$.

\subsection{Biocompatibility evaluation}

In vitro tests demonstrated the nontoxic nature of the produced HAp ICC scaffolds. One day after cell seeding, cells showed $(56 \pm 7) \%$ of adhesion. The osteoblasts adhesion onto the ICC surface is a necessary step before proliferation and further differentiation. Throughout the 10 days of culture, an increase in the resazurin test absorbance values was observed, corresponding to a proportional increase of the cell number (Fig. $2 \mathrm{~F}$ ). This shows that the samples were able to promote cellular proliferation. Fluorescence microscopy confirmed that osteoblasts were able to attach, proliferate and inhabit the scaffolds. The abundance of stained cells (bright spots corresponding to cell's nucleus) indicates a good viability (Fig. 2D and E). . 


\section{Conclusions}

Ceramic porous scaffolds with ICC geometry were successfully produced based on a simple sol-gel route. The fabricated scaffold composed of HAp/ $\beta$ TCP showed an ordered pore structure that inversely replicated the microspheres' template, exhibiting macropores sizes of $196 \mu \mathrm{m}$ in diameter and a porosity of about $80 \mathrm{vol} . \%$. Osteoblasts ability to attach and proliferate within the scaffold reveals a favorable environment for bone ingrowth. Thus, the structures designed present interesting features that upon further development can lead to new products for bone tissue regeneration.

\section{Acknowledgements}

This work was funded by FEDER funds through the COMPETE 2020 Program and National Funds through FCT - Portuguese Foundation for Science and Technology under the project number POCL-01-0145-FEDER-007688 ref: UID/CTM/50025. Carlos F. C. João acknowledges FCT for his scholarship ref: SFRH/BD/80860/2011.

\section{References}

[1] Hutmacher D. Scaffolds in tissue engineering bone and cartilage. Biomaterials 2000;21(24):2529-43.

[2] Dorozhkin SV. Bioceramics based on calcium orthophosphates (Review). Glass and Ceramics 2007;64(11-12):442-7. doi 10.1007/ s10717-007-0109-1.

[3] Yang S, Leong KF, Du Z, Chua CK. The design of scaffolds for use in tissue engineering. Part I. Traditional factors. Tissue Engineering 2001;7(6):67989. doi $10.1089 / 107632701753337645$.

[4] Choi SW, Zhang Y, Xia Y. Three-dimensional scaffolds for tissue engineering: the importance of uniformity in pore size and structure. Langmuir 2010;26(24):19001-6. doi 10.1021/la104206h. 
[5] João CFC, Vasconcelos JM, Silva JC, Borges JP. An Overview of Inverted Colloidal Crystal Systems for Tissue Engineering. Tissue Engineering Part B: Reviews 2014;20(5):437-54. doi:10.1089/ten.teb.2013.0402.

[6] Franco PQ, João CFC, Silva JC, Borges JP. Electrospun hydroxyapatite fibers from a simple sol-gel system. Materials Letters 2011;67(1):233-6. doi:10.1016/j.matlet.2011.09.090

[7] Ratner BD, Hoffman AS, Schoen FJ, Lemons JE. Biomaterials Science. An Introduction to Materials in Medicine; Academic Press; 2012. ISBN 008087780X.

[8] Fathi MH, Hanifi A. Evaluation and characterization of nanostructure hydroxyapatite powder prepared by simple sol-gel method. Materials Letters 2007;61(18):3978-83. doi 10.1016/j.matlet.2007.01.028.

[9] Fathi MH, Hanifi A, Mortazavi V. Preparation and bioactivity evaluation of bone-like hydroxyapatite nanopowder. Journal of Materials Processing Technology 2008;202(1-3):536-42. doi 10.1016/j . jmatprotec.2007.10.004. 

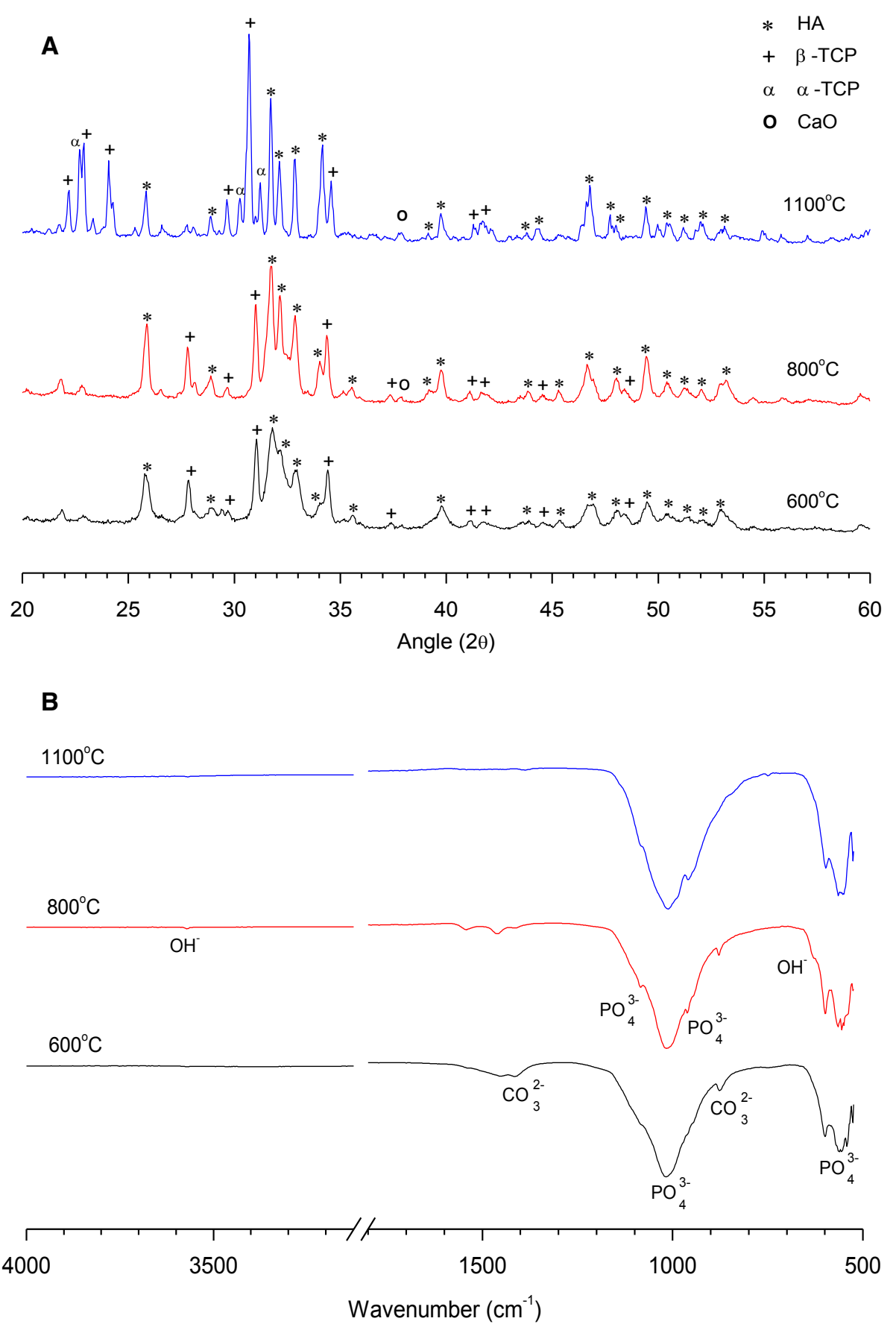

Fig. 3: Difractograms (A) and FTIR spectra (B) of HAp ICCs sintered at $600^{\circ} \mathrm{C}, 800^{\circ} \mathrm{C}$ and $1000^{\circ} \mathrm{C}$. The diffractograms show the increase of crystallinity of the ceramic but also the evolution of the composition towards a HAp/ $\beta$-TCP biphasic ceramic with increasing sintering temperature. 